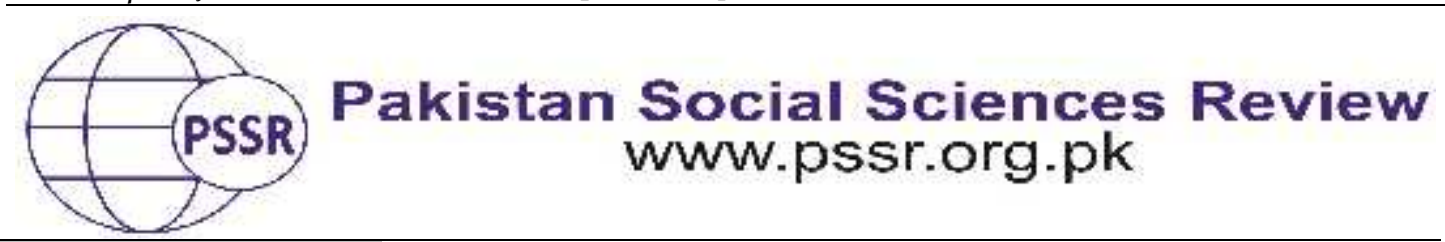

RESEARCH PAPER

\title{
An Exploration of Postcolonial-Feminist Elements in William Dalrymple's White Mughals
}

\author{
Saman Nasir ${ }^{1}$ Muhammad Ajmal ${ }^{* 2}$ Marya Sarwar ${ }^{3}$
}

1. Assistant Professor, Department of English, Women University Multan, Punjab, Pakistan

2. Assistant Professor, Department of English, University of Lahore, Punjab, Pakistan

3. Lecturer, Department of English Language and Literature, University of Okara, Punjab, Pakistan

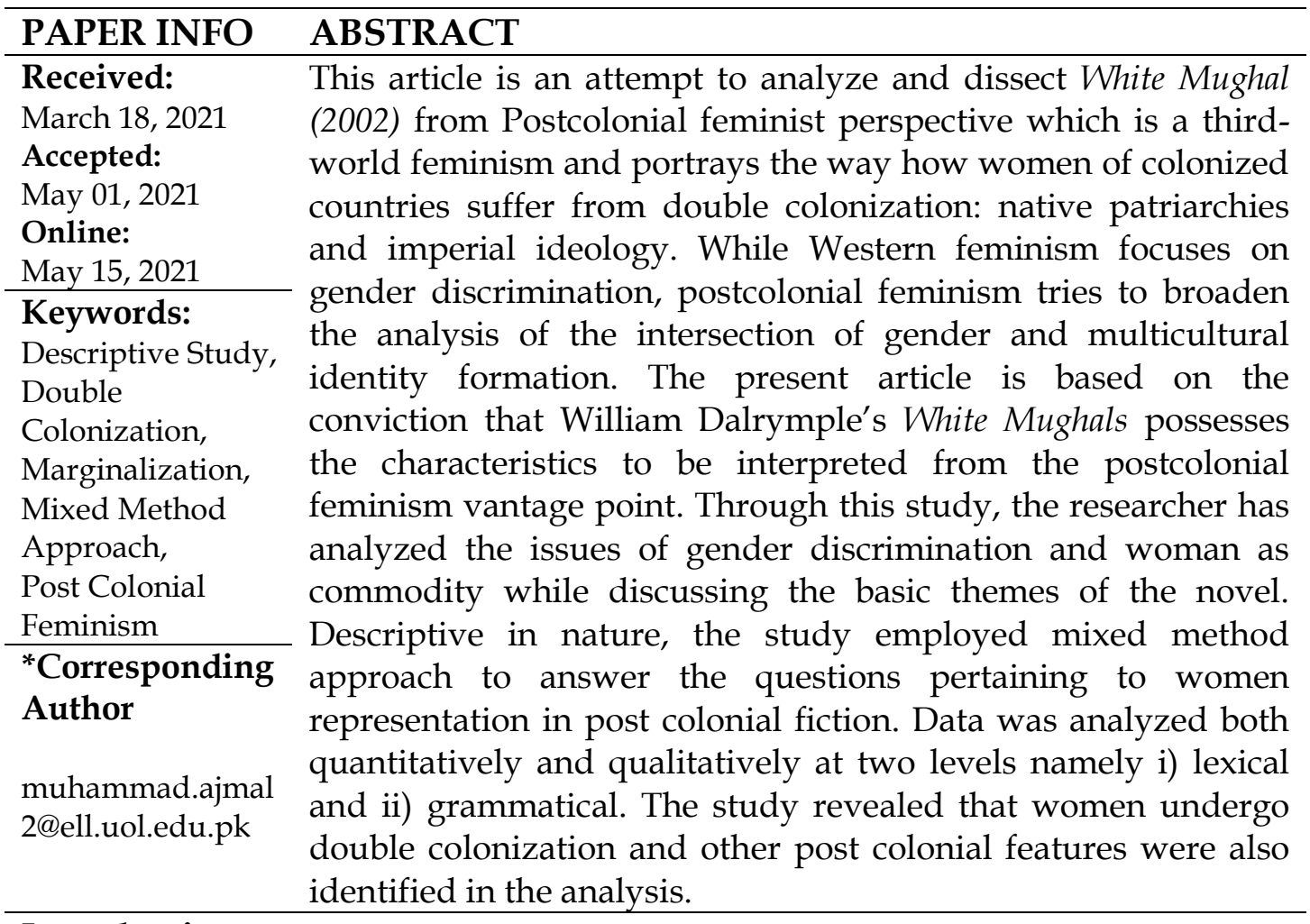

\section{Introduction}

Post colonial feminist study deals with representation of women in the post colonial world where they undergo double colonization. Post-colonial literature as such got its root from the Britain's earlier colonies of Caribbean, Africa and India. It is a kind of literature produced by both colonizers and the colonized under the impact of colonial rule. Each category of post colonial writer presented reality through their specific lenses. After liberation from colonial rule, various writers of post-colonial literature wrote in English and their theme of writing was struggle for 
freedom, national unity and identity, national adherence, emigration and youth. In the post colonial literature a number of discussions and debates were held for the selection of topics and themes that were new and essential for the readers of post colonial literature. It concerns many issues of society that works on national unity and strength, cultural adherence and above all the lack of confidence on self.

Post colonial literature is built on a theory of literature that functions on critical inquiry and works of literature under the impact of colonialism. It also works on literature written by writers and literary workers of colonial countries that work on the subject of colonies and their own people. The theory laid its foundation on the subject of 'otherness' and 'resistance'.

Baofu (2012) believes that major facet of post colonialism is either vicious or conflicts of culture, which were the result of earlier colonial times. For a long time, colonial dictators had been imposing their values on the people of that country. Even after the independence of the people of that country from colonialism, the colonial values were perceived to be present in their way of living and should be removed in order to practice their independence. The main focus of post colonialism was to expose the racial and ethnical discrimination meted out toward the natives. It reveals the diverseness of places being colonized, by studying the coarse effects of western countries on places, natives and societies of countries that were under the throne as colonies in the past. It laid special focus on European colonies especially in context of Asia, Africa and American continent.

\section{Literature Review}

This section deals with the theory and practice relevant to carrying out a post colonial and feminist study together. It takes an extensive view of the major concepts like feminisms, its kinds, different phases and post colonial theory. As such the current research is the study and evaluation of colonialism, imperialism, feminism and postcolonial feminism. Post-colonial feminism is termed as third world feminism. The main focus of the study is on post colonial society in reference to feminism as its prime aspect to be studied. The research would be premised upon the view of the east and the west according to which the latter frames binary extremes and give theoretical background of history of feminism, its roots and branches and role of women in writings and novels. Illustration of feminism is the means through which the literature structures people, places, events, happening and cultures from reality. Feminism is a component of social philosophy for over a large period and since last four decades position of women and their human rights has been continuously changing in the west. But, the depiction of women is still a constant subject of interest. Females are depicted in reference to their beauty, sexuality, feelings, emotions and care. The foremost concern in women is for her physical beauty that masks their inner self and beauty. This may not be applicable to many women in their daily life. It is a part of a women role to be caring toward her family while men are free from this responsibility. 
Colonial discussion is mainly based on the foundations of Europe and on the notion that had cause modernity in former colonies. Colonial discourse is all about colonies, colonial populace, colonial power and the relation between the colonizer and the colonized It is all about the knowledge, history and details about colonized world. It is made and developed within the society of the colonizers within which the colonized also have a view of them. It develops a disagreement due to other sorts of knowledge of the world into the minds of the colonized people. A set of rules should be developed due to the superiority of colonizers on their way of living and the needs of the colonized for raising their way of living by colonial contact.

Feminist theories are full of conflicts and diversity of ideas. They have altered the way of defining and using of discourse in our writings. Discourse, understanding post-colonial theory calls for subjecting it to means of diverse knowledge and feminist viewpoint is highly relevant here. It is now used for the purpose of resistance and interpretation. By the detailed examination of discussion, it became clear that surface meaning of a text is not the only meaning being used. No doubt understandings or knowledge removed from the context are of equal significance as those within the contexts. Hence, both the theories have caused conflict with the Said's (1993) homogenizing analysis of colonial texts. The basic aim is to acknowledge the rule not in a sense of rulers and slaves but instead in the acknowledgement of role of people in gathering colonial understanding and confrontation also in a sense to create a better model of political discourse. Colonialism is known as a condition in which one culture or country occupies another country and imposes on them its own governmental rules and structure. It is better explained in the terminology of imperialism, like invasion over the trading system to make them trade against their will, to force them to practice their religion and so on. A number of colonial and imperial relations were imposed on them but they were not made to make separation between them. Being on one side of the prime discussion seems incomplete in apprehending of the text.

The term post-colonial feminism is rooted in oppressions of racial, ethnical and sexual nature and is present in different colonized societies that are why known as post-colonial feminism (Tolen, 2006). It has analyzed various aspects of women life including their identity and sexuality with the gender, nation, class and race, in the guidance of colonialism and neo-colonialism (Navid, 2014). Women in this literature are shown in stereotypical roles such as domestic chores, marginalized entity, submissive and weak. In this study, information relevant to woman's role in a colonial period is investigated so as to see whether feminism has made any perceptible advance from the past to the present day world in India. The Indian continent is a hot bed of various ethnicities each having diverse social customs and treatments toward their women.

Tyagi (2014) defines post colonial feminist theory as primarily concerned with representation of men in once colonized countries and in western locations. Post colonialists aim at exploring discourses misrepresenting them as inferior, 
whereas feminists seek to liberate women from double colonization. The theories of feminism and post-colonialism have evolved independent of each other but to adapt and overcome to the same situation. They have many similarities with respect to the route they adopt but they are not overlapping. Within the last decade, a keen focus was given not only to their similar route but concern was also given to their real and ideal [p-overlap. Feminist theory had searched for suppositions that are not at all investigated in the post-colonial discussions, such as the investigation of scholarships to be offered to Western feminism. It had given new targets and admonition.

By feminism in double colonization we mean that females are oppressed and subordinated by colonizers rule and male rule, which has taken importance among post colonial and feminist systems in 1980s. But, work on double colonization as a theory started only a few times back. Ketu Katrak has focused, the inescapable importance of putting up feminist political affairs into the societies, that are colonized. Women's cultural and ideological relationship has been discussed through scientific, literary, juridical, linguistic and cinematic discussions.

Mersha (2004) worked on the postcolonial feminism by finding and defining the role of black and women perceptions and awareness in the novels and writings of various novelists from all around the world particularly Africa, USA and the Caribbean. He further stressed 'to enrich the knowledge of Black feminism, to show the common experiences of Black women almost in the world and to give insight to the development of Black feminism'.

The work of Fekadu (2005) expressed that women are targeted to the issues of repression by sex and class due to their particular societies. Women are always objectified and the role of female as a result of physical and sexual needs of men. Females in one way or another are an object of pleasure of males and suffer oppression.

Mulualem (2006). he considers feminism is a support of women of Africa in socio-political perspective. He stressed that expression of oppression of female by the natives of colonizer's societies and male rule does not explain their position and their suppressing household activities rather we should root out the manly activities by excluding such occurrences from the novel.

Tesefalidet (2007) examined the sufficient illustrations of discriminatory attitude towards female by males of the society in the writings and also showed that their oppression on females crosses its boundary and had influence on life of females.

Itana (2007) showed the image of women in the western novels which shows that they should be defined in their own terms irrespective of their comparison to men. Dalrympleshowed the same in his novel that women of the colonized societies particularly in South Asia are marked as target to the double colonization, however they are a separate entity and should be treated likewise. 


\section{Theoretical Framework}

Post colonial feminist studies are being carried out at different places in the world. .The work of pioneering nature by Ashcroft et al(2006) and Mirza (2009) constitute the theoretical basis for the present study. Every sound research fulfills the question of validity and reliability so is the case with the present research which descriptive in nature.For the analysis and evaluation of the text the researcher has used lexico-grammatical approach which takes into account linguistic data at lexical as well as syntactic level. Selection of lexical items having post colonial or feminist underpinnings would be made quantitatively and manually. The selected items would then be analyzed through binary oppositions.

\section{Results and Discussion}

The analysis is carried out at two levels namely lexical and grammatical. Authors choice of specific lexical items and grammatical structure could be a point of departure for an extensive interpretation. How men and women are represented depends on the authors and their approach to choose in order to indicate the discrimination regarding gender. A word may have different way of implication both for men and women. In case of women its implication would be more sexual and congested. Following are some of the examples:

a. Boys will go to West for his proper brought up.

b. Girls would be kept at home like her mother to learn households.

The labels or role we allocate to women are always congested whereas in case of men they are always broad. This shows the role of language for putting down women.

The main goal of this description done above is to find out any discrimination toward women in terms of language mentioned in the novel- White Mughals. In order to find it out, subject or content analysis and evaluation of words, phrases, clauses, adjectives and pronouns would be done. Following are the features taken into consideration for seeking answers to the research questions framed for the present study.

- Identifying characters of male and female

- Representation of gender by use of adjectives

- Representation of male role and female role by pronouns

The researcher analyzed all the ten chapters of the novel and concluded that more importance is given to male characters than female as the number of male characters is overwhelmingly higher than females. The proposition that it is a 'man 
made world' bears truth keeping the findings regarding the above variable. So proper representation for female is either missing or the women in the society under reference are restricted only to a few marginal roles.

Throughout the novel it was observed that adjectives used for females are more in number than males. So there is subsidiary representation of females which shows that the language of the text reinforces gender discrimination. Use of less adjectives for males connotes to an already established position and roles for men whereas the case is otherwise in case of women. They are described each time with adjectives so as to win a place for them in the patriarchal society of India.

It was observed that first person pronouns are used for males while third person pronouns are used for females which indicate that there is gender discrimination in the text. Males have power over females. The use of first person pronoun further indicates a confirmed position of authority. For the obtaining of benefits, we should distinguish between different aspects of a subject, whether those aspects are institutional, economical, political or any other.

The view that females are inferior and male are superior is to preserve position and power of man in social, economical and political perspective. It would be better said as, in order to keep women under control it is necessary to maintain their perception of themselves as weak and powerless. They are kept weak by not giving them education and equal position in jobs to refrain them from social, political and economical control. Their weak place in the society is not biologically fabricated instead it is the result of culture. It is also a result of male rule over female that it is realized to others that hysteria is more prevalent among females as compared to male. It is the result of our belief that no case of male was diagnosed, otherwise male and female had equal chances of the disease. If diagnosed it would be diagnosed as any other disease. They may be detected as suffering from the problem of short temperament. Patriarchal view is not accepted and recognized by every man. They believe that it is not necessary if males are given strong body they may be strong in every field.

The researchers analyzed the use of pronouns specifically first person pronoun in order to show discrimination between both genders and inequality toward woman. It had laid main emphasis on post-colonial society. It blurs the picture of women. Societal experiences are depicted in them, so they illustrated the situation of the society. The study show the use of adjectives in illustrating gender differences and biasness toward females with respect to gender. It is simple and precise, guides contact and supports thinking. It is noteworthy that it gives authority by greater use and contradicting it on other side it permits exchange of information.

\section{Lexical Analysis from Post-colonial Feminist Perspective}

A descriptive analysis is being provided on the basis lexical as well as grammatical features explored in the selected texts. 


\section{Sexual Objectification}

The theory was given by Fredrickson and Roberts in 1997. It gives a structure for understanding the practices and thoughts of female within the perspective of society when she undergoes labeling for her physical characteristics. It is essential for research study within field of psychology of women and the field of counseling and guidance. These fields work on the target of justice to women. It motivates psychologists to work for the welfare of women, their experiences, understanding of situation, ways of coping and opposing against the problem of sexual objectification.

The two resulting newspapers- or Akbar - accused James not just of sleeping with Khair-un-Nissa but of raping her, and of using his position to force her mother and grandfather to hand the girl over to him for his pleasure.

"Indian women were regarded throughout the Middle East as being especially sophisticated in the arts of love, so they were believed to be especially skilled in the art of preventing pregnancy, and if all else failed ,in assisting at births".

Women are viewed in terms of their role they play in society and the labels that are attached to them with respect to their sexuality or physical characteristics. It encourages inappropriate labeling of characteristic whereas the labels that are most appropriate and referential are ignored. A commodity or sex object as presumed by the people outside Asia is the false belief inculcated in the minds of the world because of objectification of women in this part of the world. They are generalized to house jobs for the pieces of work people are paid outside their home. It includes jobs of cooking, gardening and accounts of bills and taxes.

Shushtari was of the opinion that European women were particularly bizarre, immoral and headstrong creatures:' most European women have no body hair', he notes, And even if it does occur, it is wine-colored, soft and extremely fine.... By reason of women going unveiled and the mixed education of boys and girls in one school-house, it is quite the thing to fall in love. (p. 166)

The use of lexical items like bizarre, immoral and headstrong creature clearly marks the attitude toward women. A male can neither judge him perfectly not the female but the use of declarative sentences shows authority on the part of the speaker. The differences with respect to language give rise to labeling of sexes. In many societies women are attributed with many proverbs, jokes and humors. In the west female have no hairs on body illustrates that they are describes of their sexuality and they are an element of pleasure. Sexual objectification theory shows that the experiences of female are directed by their roles and position in society. There are individual differences as well among women. All women are not affected by their genetic, hormonal and anatomical differences in female body. Their physical characteristics and sexuality is labelized. They consider their physical characteristics as significant in defining themselves and recognition for society. Adjectives are used in the text to illustrate differences among male and female such as "bizarre", 
"immoral" and "headstrong". These adjectives are hard enough to be used for females and males as a group so they are ascribed separate categories. Similar, is the case of nouns which shows the different kind of mind-sets and structure of both male and females. As mentioned in the text are the nouns "body-hair", "winecolored" and "fine".

Sexual objectification is the name of labelizing others by mean of their physical characteristics and sexuality. They may then lack a proper identification of their personality; instead have one view about themselves which is based on the physical characteristics and sexuality. It serves as a source of enjoyment for others. It is one of the social perspectives of discrimination.

Lady Strachey describes as 'being of the Yorkshire gentry'. A portrait of Maria by Romney shows a pretty, sensual woman with full lips, long reddish hair and intelligent, knowing expressions. She and Kirkpatrick quickly had four children in as many years; but the marriage was not a success. ( $p .72$ )

With the development of gender, society attributes differently to both male and female. Attributions associated with females are with respect to their physical characteristics as they should be young and pretty. Every woman to have these characteristics is not possible. Females are always putting efforts to fulfill these attributes and in case of lack of its fulfillment they would feel inferior and imperfect. Their definition of perfection is associated with it.

Certainly it was precisely Khair un Nissa's aristocratic birth and connections that led to James's reticence on the subject to William. (p.188)

Women would be labelized with inferiority and nouns that lack respect, whereas boys would be treated with superiority and nouns that have respect. It demonstrates the role of language in degrading women.

The women of the immoral Hindus and the Muslims they have corrupted, of their own accord and desire enter into the bonds of wedlock with the English. These English do not interfere with their religion nor compel them to leave parda; when any son born of the union reaches the age of four, he is taken from his mother and sent to England to be educated. Some daughters are left with their mothers to be trained by them in their own way before being married off to a Muslim (P. 170)

The words like 'immoral Hindu and muslim' 'parda' 'daughters to be trained at home' are self explanatory of the plight of Indian women who are confined to walls where the educate each other whereas sons are sent abroad for seeking higher education and securing positions of power as they grow up. The customs like these inculcate into minds of women what they are, what they are required to do and what set of conduct is determined by the elders of the family for them. Sexual objectification is the state of taking the individual as a tool for sexual pleasure, by making them a toy. Precisely it means to demean an individual with respect to their sexuality ignoring their individual identity and respect. It is attributed both at 
societal and individual level. The elements of gender objectification mainly of women are the essential part of feminist theory and its psychological aspects. Sexual objectification creates differences among genders giving rise to inequality for women. But according to some social critics, women of modern age target themselves of objectification in order to gain empowerment on other gender.

In the evenings after returning from the hunt, Kirkpatrick would invite troops of Hyderabad's famous Nautch girls to the camp to perform. In matters of Deccani dance and music, many members of the Hyderabad residency became connoisseurs- so much so that Mah Laqa Bai Chanda, Hyderabad's most celebrated dancer and courtesan as well as the first major women poet in Urdu dedicated her Divan to one of Kirkpatrick's Assistants, Captain John Malcolm.

An alternative to nautches were the bhands (buffons or mummers). whom Elphinstone was particularly taken with when they performed after one of James's hunting expeditions. ( $p .124)$

The words like 'nautch girls, dance and music' are associative with the subcontinent where different places were synonymous with girls engaged in dancing profession and prostitution. The institution of prostitution is times old relic of the man made society treating women as a plaything or commodity. English was the language of superlative rank in India. It had fine style and element of rule in it. Words of English language had both open and hidden meaning in it. By the term connotation mean hidden meaning which varies according to societal factors. It had an element of connotation in it. Sexual connotation is also an outcome of society. Selection of words for women in the text shows a negative impression and image of women, by the nouns like "bhaands" and "Nautch". On the other hand, proper selection of words are made for men which projects respect and honor for them in society, such as "haunting expedition"

Kirkpatrick had come to meet and have an affair with a teenage Muslim noble woman who was kept in strict purdah, especially when she was engaged to be married to another man. Was it Kirkpatrick or the girl who had taken the initiative: who seduced whom? When did they first sleep together? How often? When did it become a public matter? How did the story get out?(p.8)

Lexical items like 'purdah', teenage girl' and 'seduce' are further reflective of underage marriages in the sub-continent in both Hindus and Muslim societies. The actual situation or scenario due to stereotypes and discrimination are elaborated in terms of language. The words expressing experiences are in short illustrating the cultural background of them and the practices which gave rise to them. The entire situation was pointed on to the women as it was due to her in the content lines and male's intention was masked over by appropriate use of words. 
Other Tawaifs, and the musicians who worked with them, donated guest houses for the pilgrims, mosques, ceremonial arches and naqqar khanas, as well as pools and fountains and pleasure gardens in the countryside nearby ( $p .222)$

It is beneficial to study the effect of societal values and elements on the structure and function of elements of language. Lexical items like 'tawaif' 'naqqar khan' and pleasure gardens' illustrate the traditions in India. Lucknow, a renowned cit for Tawaaifs and sond renditions accompanied by dances of girls attracted many foreigners towards India. The insignificance of women in its street is a common spectacle.The elements of society that effect language are age, class, societal relationships, race, ethnicity and religion. The quantity and ratio of nouns used vary from place to place. For example, noun used in the content are "pilgrim" and "mosque". This shows the effect of society and geography on the selection of words and language.

\section{Colonel Browser testified that Kirkpatrick had personally told him that...}

In consequence of this intercourse the young lady became pregnant, and to conceal her disgrace they (her family) wished to marry her to a Musleman formerly alluded to (the son of Ahmad Ali Khan). but the lady herself had positively refused, had threatened if compelled to put an end to her existence, and declared that she would marry no person but James Kirkpatrick.

James had grudgingly admitted to William that he had slept with Khair-un-Nissa but denied that he was planning to marry her, or indeed that he regarded his connection with her as anything more than a regrettable lapse of self-control ( $p$. 235)

The sentence structure of female had no logic or power. The novelist had simply explained the feelings in a frameless way having no format. On the other side, sentence of male explanation had power and preference. The novelist had done so in a proper way by added certain aspects and removing others. The novelist expresses authority, power and boldness, whereas in case of female they show lack of control, has feeling and passiveness. Female practices are more about their relationship while male practices is not concerned with so. Male practices and experiences are concerned with himself. The content expresses that male individuals of the society can objectify female and may affirm it as his negligence. Patriarchy signifies an already determined role for man to exercise his will whether justifiable from any canons of morality or not. The decisions from home to business places are in the hand of the family elders who even betrothe young girls to elderly men for the sake of their honour.

Other Indian women who had married British Residents at this time had found that marriage brought them prestige, wealth and rank (P. 182).

The nouns of high social positions and attitude are depicted in male sentences, such as nouns of prestige and wealth. But, the nouns of low social positions and attitude are depicted in female sentences. Marriage had a great role in Subcontinent due to the influence of society and social and political factors. Men 
have to maintain his profession and job in order to establish his financial status which women of the society are looking for in their marriage. The text, under reference, points to the fact that economic needs play a great role in winning due rights for people. Poor girls are marrying the 'others' the English men for the sake of power and prestige and moreover for economic security and their well being.

William Hickey's relationship with his Bengali bibi Jemdanee is a good example of the sort of relationship a Calcutta nabob might form with an Indian woman at this time. The relationship started as one of simple concubinage. Hickey makes no bones about the way he inherited Jemdanee after a neighbour returned home to England: 'I had often admired a lovely Hindustani girl who sometimes visited Carter at my house,' he writes in his Memoirs.(P. 37)

The text given above indicates another hideous side of colonial and patriarchal mindset. A sweeper woman was exploited by the Englishman for no reason other than sexual objectification of women in special south Asian context where concubines are traded in streets of major cities. The very line with first person pronoun 'I had often admired a lovely Hindustani girl who sometimes visited Carter at my house,' is self explanatory of the attitude shown towards women on behalf of the English ruling class in India.

William Wa living with an Indian woman, Dhoolaury Bibi, by whom he fathered two Anglo-Indian children, and with whom he maintained a relationship until the end of his life, despite being married to an English woman-Maria Pawson-for twelve years in the middle. (P. 67)

\section{Discussion}

The text given above is also a reflection on the lecherousness of males and sexual objectification of the females in the colonial period. William, despite marrying an English girl, marries an Indian girl to satiate his sexuality. The opinion of the girls he married has not been made vocal at any place which shows women both European and Indian are object of colonization. Their colonizers abused them as they did with the territories they rules and in the same fashion as if they were their masters.

\section{Textual Lines}

Baqar Ali Khan had one daughter, a young widow named Sharaf un Nissa, who had unusually returned to the family deorhi with her two teenage daughters after the death of her husband Mehdi yar Khan. Like her father, Sharaf un Nissa appears to have been very well disposed towards the British, and used to invite the wives of the Company officers to visit her in her zenana. (P. 154) 


\section{Discussion}

The text given above refers to another sad fact of colonial and feminist reality pertaining to the life of women after the death of their husband. As a widow they are more miserable creatures than the younger girls. In the absence of their sustainer and bread winner, they are supposed to return to their paternal homes to live a miserable life of dependence and subjugation.

\section{Major Findings}

The illustration of women on the basis of what roles are assigned to them in a societal set up illustrates that language determines their position either superior or inferior. Most of the world literature has been produced by men who portrayed women as they perceived them. They are perceived as inferior or lower in status to men and this perception is generated through the attributes attached to them by men; this as a result built up certain stereotypical notions in the mind of general public. Different profession are opted only by men is an indicator of the world being defined by men. Women do not occupy certain titles but act as an adjective to that title. As for example, pilot is used for male, in order to use the title for female they have to use adjective with it as female pilot. It shows that they are out of order or rhythm. In case of sentences, female sentences are short of power and wisdom. They use feelings and less structured or ordered sentences. While discussing male sentences there is an element of power and rationality. Men employed an implicit power of choice in selection of lexical items to include to delude the content they want. Their sentences have an element of clearness and wisdom. The writer of sentences has power and authoritarian style. They are more direct whereas females are full of feelings and regard. Female sentences depicting female experiences of life are mostly about relations and association, whereas male sentences depict male experiences of life. Language to a great extent is affected by society and culture, so language and social structure is also interconnected. A number of elements of language are the result of socio-economic factors.

Differences in speech are associated with the labels we associate with their gender. As for example, it is said females of west do not have body hairs due to the fact that they are perceived as a source of pleasure to the West. Objectification theory states that how attributing labels to their role affect their behavior. It shows the differences among women that not every woman is affected by their biological differences. Differences may be with respect to hereditary, hormones and structure of the body. Changes in their thinking pattern and behavior are not brought about abruptly. Instead, women learn to do so. Women will then attribute their appearance and would also suppose that others will also do it. By the term sexual objectification we mean labeling others by mean of their sexuality. As a result of which an individual fails to recognize themselves instead they considers their outer appearance only. Due to this, people feel pleasure by targeting others. It is a result of the social factors of society. Sexual objectification is the state in which people considers other as a source of sexual enjoyment by making them an object of sex, by masking off their identity and personality. It is done at the state of society but could 
also occur at the state of individual. The elements of gender objectification mainly of women are the essential part of feminist theory and its psychological aspects. Sexual objectification creates differences among genders giving rise to inequality for women. But according to some social critics, women of modern age target themselves to such objectification in order to gain empowerment on the opposite gender.

\section{Conclusion}

The present study was carried to find the ways how women are represented in post colonial fiction. The role of feminism or gender differences assuming the shape of a kind of racism and colonialism in the subcontinent among West and the East has been viewed in the study. The basic aim of this study is to analyze linguistic element in the novel so as to identify and highlight differences on the basis of gender. For the achievement of this purpose content analysis is done of words and grammatical choices in order to find out the reality within the perspective of feminist perspective. The basic concept in it was to see women when taken as a general group, it is then explained universally by gender perspective. It is not defined with respect to society, ethnicity and race. Post-colonial feminism is a new concept developed by post-colonial theorist, who studies the impact of colonialism and imperialism on the experiences of people of the nineteenth century. This reveals the hidden forms of burden and cruelty imposed on women as a result of society.

Women are demeaned with respect to their roles and characteristics. They are more generally labelized with nouns that lack respect and are common in society, whereas they should be called by nouns that have more appropriate. It demonstrates the role of language in post-colonial feminism women. This shows the inequalities and discriminating attitude toward both genders. It is still present in our societies by refraining women to have equal opportunities for positions. Women role in the society is an extension of the male ruling desire. They want to empower women's sexuality in order to mask risk toward their own sexuality. White Mughals illustrated well the feminist concept of double colonization. Women are subordinate to two enteritis namely the colonizers and the patriarchy at home which does not allow her to exploit her potentials. Women are ruled over by male power in respect to social, political, psychological and economical perspective. It is due to patriarchal view of society. In every era men rules and females are controlled. She is targeted and discriminated. She is identified with respect to males and is described by the possession and characteristics of male. Every experiences and activity of life are influenced by gender. It includes the experiences and construction of writings as well, whether it is within the awareness or not. 


\section{References}

Ashcroft, Bill, Gareth Griffiths \& Helen Tiffin (1998). Key Concepts in Postcolonial Studies, London: Routledge

Ashcroft, Bill, Gareth Griffiths \& Helen Tiffin (2007). Key Concepts in Postcolonial Studies, London: Routledge

Baofu, Peter (2012). The Future of Post-Colonial History, A peface to a new theory of Universality and Relativity, United Kingdom, UK: Cambridge, Scholars Publishing

Biddiss (1970). The Post Colonial Studies. London: Routledge

Blunt, A. \& Rose, G. (1994). Writing Women and Space: Colonial and Post-Colonial Geographies. New York, London: The Guilford Press

Cameron, Deborah (1998). The Feminist Critique of Language, Language Arts and Discipline, London and USA, Routledge

Chapman, R. (1973) Linguistics and Literature. London: Edward Arnold

Fekadu, K . (2005). Major Themes in the Works of Four Women Writers. Addis Ababa University.

Itana, R. (2007). The Portrayal of Women in Osmane Semben's God's Bit of Wood and Ekewens Jange, Addis Ababa University

Karen, Armstrong (2002). White Mughalss. India: Peguin Books

MacDonald, Heran (2002). White Mughalss. India: Peguin Books

Mills, S. (2002). Feminist Post Colonial Theory: A Reader. Edinburg Press.

Mishra, R. K. (2013). Post-Colonial Feminism: Looking into within-beyond-to difference: International journal of English and Literature: MTS Deemed University, India.

Mulualem, D. (2006). Aspects of Feminism in Amadi's The Concubine and The Great Ponds and Emecheta's Second-Class Citizen: A Post Structuralist Approach. Addis Abada University.

Navid, S. (2014). Critical Theory Today: A User Friendly Guide. (2nd edn.). New York: Routlege.

Said, Edward (1993). Culture and Imperialism, London: Chatto and WindusSaid, Edward and The Post Colonial, Bill Ashcroft and Hussein Kadhim, Nova Science Publishers, Inc. Huntington, New York

Soueif, Ahdaf (2002). White Mughalss. India: Peguin Books 
Siddique, S. (2014). Language, Gender And Power, Oxford University Press

Tesefalidet, T. (2007).The Portrayal of Major Female Characters in Four AfricanNovels. Addis Ababa University.

Theime, J. (2003). Post-Colonial Studies : The Essential Glossary . London, Arnold.

Tolan, F. (2006) ."Feminisms" Literary Theory and Criticism.Ed. Patricia Waugh. New York Delhi : Oxford University Press.

Tyagi, R.(2014). Understanding Post-Colonial Feminism in relation with Post-Colonial and Feminist Theories. Pondichery University India.

Walder, D. (1998). Post-Colonial Literatures in English, Oxford University Press

Young, R (1994). Liminal Postmodernisms. Colonialism and the Desiring Machine. Amsterdam, Atlanta: Rodopi 